\title{
Minimizing the Risk in Investment Projects
}

\author{
Reza Nazari ${ }^{1}$
}

\begin{abstract}
Investors must consider and explore two main parameters which are efficiency and its risk in investing and forming the optimal portfolio and select the optimal portfolio in base of these two parameters, and also by attention to these parameters try to optimize the two-parameter model. Through the present research, the quality of forming the different portfolios from diverse stocks for minimizing the risk of portfolios collection was explored. The hypothesis is that each portfolio's risk formed from a collection of different stock risk is stated as the identified function. The identified function just depends on the investment's value which was done for considered portfolio's forming and the total portfolio's risk is a function of collection of separated risks of components of that portfolio. The main discussion of the present research is the nonlinear minimizing two-parameter which can be changed as a minimizing one-parameter issue for different identified goal function. The functioned researches have proved the optimizing two-parameter model both weakly and strongly by ignoring one of the parameters. Changing the two-parameter-optimizing issue as the single-parameter issue is one by the usefulness functions and risk.
\end{abstract}

Key Words: Financial Markets, Speciffing Optimal Attribution, Forming the Portfolio, Two-Criteria Issues, Single-Criterion Issues, Goal Function, Complete Risk.

\section{Introduction}

The continuum economic development is the field to invest in determinant country and is its development outlook in the financial marketing. So, scientific exploration is the outlooks of development and familiarity with economic and mathematic models and codification of new models from important issues.

The convergent process of Azerbaijan's economic is accompanied with world economy and investment process of incomes accessed from energy part near the economy parts of some foreign countries and also macro investment of foreign investors on the stokes published by different companies of Azerbaijan. The total volume of capital which has been specified as stock in Republic of Azerbaijan is more than two billion Manat. A part of this investment was done by different companies and the other part was done by international company; which includes the other structures. Therefore, functioned investments on the stock stated the necessity of forming the different portfolio of investment like the different economic fields.

Financial management of mega-corporations consider their independent activities in some separated investment plans in front of lack of damage to public profits of megacorporations with financial activities of the membership companies. In this position, it is necessary that the main economic indexes of investments and its results in both common 
and independent investments are according to profits of mega-corporations and supply the membership companies' profits. So, it is possible to see the functioned portfolios' public indexes as their functional indexes.

\section{Minimizing the total risk of portfolios}

It is seemed that, the $\mathrm{m}$ number of existed special stocks in the financial market share attracted for investment. In this condition, we should accept the below conditions: 1- The stocks existed in the financial markets were divided to groups in $\mathrm{n}$ numbers and numbered in this group as $1,2, \ldots ., \mathrm{n}$.

2- $\quad$ Each i portfolio can be formed with one of these groups.

3- $\quad i$ investment with $\mathrm{j}$ groups will include the special risk, and this risk not only does depend on the capital depended on $\mathrm{x}_{\mathrm{ij}}$ portfolio but also can be stated with $\mathrm{R}_{\mathrm{ij}}\left(\mathrm{x}_{\mathrm{ij}}\right)$ function.

$\mathrm{R}_{\mathrm{ij}}\left(\mathrm{x}_{\mathrm{ij}}\right)$ are functions can determine the limited value for $\mathrm{i}, \mathrm{j}$ indexes.

4- The total risk of investment equals with total portfolio risks with $m$ numbers.

5- The value of capital for all portfolio is limit and equals with $\mathrm{k}$. investment in this situation will be explored from two points of views:

A) Determining that each portfolio will be formed by using each group of stocks.

B) Determining the method of distributing the capital to $\mathrm{k}$ value among the portfolio. Determining these two factors depended on determining the group of portfolios which include the least value of risk.

For exploring the issue as a formula in the best way, below variables were used:

$a_{\mathrm{ij}}=\left\{\begin{array}{l}1=\mathrm{a}_{\mathrm{ij}} \text { while the } \mathrm{i} \text { portfolio would be formed from } \mathrm{j} \text { group stock } \\ 0=\mathrm{a}_{\mathrm{ij}} \text { while it is apart from it. }\end{array}\right.$

1 - If we form the matrix A with determined number by each method, according to the number

2 - in each line of matrix just one element should be equal with 1; that is,

(2) $\sum_{j=1}^{n} a_{i j}=1, i=\overline{1, m}$

In this condition for the matrix, the total risk of portfolio will be as below:

(3) $\sum_{j=1}^{m} \sum_{j=1}^{n} a_{i j} R_{i j}\left(x_{i j}\right)$

The frequency of $\mathrm{A}$ matrixes $\mathrm{m} \mathrm{X} \mathrm{n}$ size which include $\mathrm{a}_{j}$ details are shown with $\mathrm{T}$ sample and supply the condition (1). In this condition, we will access the portfolio for each matrix A which is taken from $\mathrm{T}$, and in this kind, the total risk will be stated by (2). On the other hand, since the total risk of portfolios which are suitable for each matrix of 
$A \in T$ depended on the value of the determined capital of $\mathrm{x}_{\mathrm{ij}}$ of stocks, it is necessary that the capital will be distributed among the stocks which total risk would be minimized; that is, for each $A \in T$, the below phrase determines the total minimum risk:

$$
\sum_{j=1}^{m} \sum_{j=1}^{n} a_{i j} R_{i j}\left(x_{i j}\right) \rightarrow \min
$$

Therefore, it can be said that: the total portfolio risk depended on two factors: "selecting the matrix A" and "the style of capital for selected matrix". This shows the mathematic model of exploring issue as below:

The $A^{*} \in T$ matrix and the values of $x_{i j}^{*}, i=\overline{1, m} j=\overline{1, n}$ capital should be found:

$$
R\left(A^{*}\right)=A \in T\left\{\begin{array}{l}
\sum_{i=1}^{\mathrm{m}} \sum_{j=1}^{n} a_{i j} R_{i j}\left(x_{i j}\right) \rightarrow \min \\
\sum_{i=1}^{m} \sum_{j=1}^{n} a_{i j} x_{i j}=K \\
\sum_{j=1}^{n} a_{i j}=1, i=\overline{1, m} \\
x_{i j} \geq 0, \quad i=\overline{1, m} ; j=\overline{1, n}
\end{array}\right.
$$

The minimum value in condition (4) would be sought in directions which supply the conditions. The matrix A taken from the frequency $\mathrm{T}$ states the optimal distributed issue of the $\mathrm{K}$ capital.

In base of principals, solving the issue (4)-(7) will be possible by selecting the details of the frequency $\mathrm{T}$ with solving the issues in $n^{m}$ numbers. The issue of solving the issues separately, since the issue is optimal distribution of capital; by "complete selection" style will include some complications. So, the necessity of solving the issue will be stated with methods which the number of less selections will be asked.

With accurate look, it is determined that the structure of (4)-(5) can be changed to a single-parameter issue with simple structure by a series of changes of an issue. Here, the steps of changes are described. For this, a matrix $\mathrm{A}$ is taken from $\mathrm{T}$ frequency. For simplifying the issue, the matrix A supplies the below conditions:

$$
a_{i j}=\left\{\begin{array}{l}
1 \text { if } \quad \mathrm{j}=1 \quad \mathrm{i}=\overline{1, \mathrm{~m}} \\
0
\end{array}\right.
$$

Note: If there is $j=1$ and $i=1, m$, the values of $a_{i j}$ will be equal with 1 and on the other hand it will be equal to 0 . Suitable with this matrix, we write the issue (4)-(7) (the optimal distribution issue of capital): 
$\min _{x_{11}, \ldots, x_{1 m}}\left\{R_{11}\left(\mathrm{x}_{11}\right)+R_{21}\left(\mathrm{x}_{21}\right)+\ldots \ldots .+R_{m 1}\left(\mathrm{x}_{m 1}\right)\right.$

$\mathrm{x}_{11}+\mathrm{x}_{21}+\ldots \ldots \ldots .+\mathrm{x}_{\mathrm{m} 1}=K$

$\mathrm{x}_{\mathrm{i} 1} \geq 0, \quad i=\overline{1, m}$

I

Now, the details of the first line of the matrix will be changed to below:

$$
\left\{a_{11}=0 ; a_{12}=1\right\},\left\{a_{12}=0, a_{13}=1\right\}, \ldots .\left\{a_{1 m-1}=0, a_{1 n}=1\right\}
$$

It is seen that in each change in the first line of A just one part is 1 and the others will be 0 .

The frequency of issues suitable with matrix will be as below by changing the matrix A according to above method:

$$
\begin{aligned}
& \min _{\mathrm{x}_{11}, \ldots, \mathrm{x}_{\mathrm{n} 11}}\left\{\mathrm{R}_{11}\left(\mathrm{x}_{11}\right)+\mathrm{R}_{21}\left(\mathrm{x}_{21}\right)+\ldots+\mathrm{R}_{\mathrm{m} 1}(\mathrm{x})\right\} \\
& \mathrm{x}_{11}+\mathrm{x}_{21}+\ldots \ldots \ldots+\mathrm{x}_{\mathrm{m} 1}=K \\
& \mathrm{x}_{11} \geq 0,1=\overline{1, m} \\
& \min _{\mathrm{x}_{12}, \ldots, \mathrm{x}_{12}}\left\{\mathrm{R}_{12}\left(\mathrm{x}_{12}\right)+\mathrm{R}_{21}\left(\mathrm{x}_{21}\right)+\ldots .+\mathrm{R}_{\mathrm{m} 1}(\mathrm{x})\right\} \\
& \mathrm{x}_{12}+\mathrm{x}_{21}+\ldots \ldots \ldots+\mathrm{x}_{\mathrm{m} 1}=K \\
& \mathrm{x}_{\mathrm{ij}} \geq 0 ; \\
& \min _{\mathrm{x}_{1 \mathrm{n}}, \ldots, \mathrm{x}_{21} \mathrm{x}_{\mathrm{m} 1}}\left\{\mathrm{R}_{1 \mathrm{n}}\left(\mathrm{x}_{1 \mathrm{n}}\right)+\mathrm{R}_{21}\left(\mathrm{x}_{21}\right)+\ldots . .+\mathrm{R}_{\mathrm{m} 1}\left(\mathrm{x}_{\mathrm{m} 1}\right)\right\} \\
& \mathrm{x}_{1 \mathrm{n}}+\mathrm{x}_{21}+\ldots \ldots \ldots . .+\mathrm{x}_{\mathrm{m} 1}=K \\
& \mathrm{x}_{\mathrm{ij}} \geq 0,1
\end{aligned}
$$

If the frequency of these issues is written as below: 


$$
\begin{aligned}
& \min _{0 \leq \mathrm{x}_{11} \leq K}\left\{\mathrm{R}_{11}\left(\mathrm{x}_{11}\right)+\min _{0 \leq \sum_{1=2}^{\mathrm{b}} \mathfrak{u}_{u=1} \leq \pi-u_{11}} \sum_{1=2}^{b} R_{i 1}\left(\mathrm{x}_{\mathrm{i} 1}\right)\right\} \\
& \min _{0 \leq \mathrm{x}_{12} \leq K}\left\{\mathrm{R}_{12}\left(\mathrm{x}_{12}\right)+\sum_{0 \leq \sum_{1=2}^{\mathrm{b}} \min _{u_{i 1} \leq \pi-u_{12}}} \sum_{1=2}^{b} R_{i 1}\left(\mathrm{x}_{\mathrm{i} 1}\right)\right\}
\end{aligned}
$$

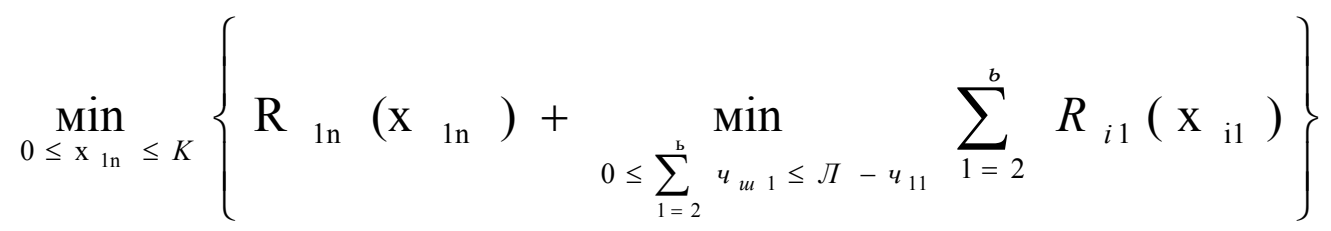

It will be seen that through the frequency of these issues:

A. The existed collections inside the braces are similar since the minimum functions in the oblast area will be determined similar.

B. In spite of the differences of the first collections inside the braces in base of the special characteristics of the second collection of similar applications as the final results, it can be said that solving the issue (12), will be equal to below solution:

$$
\min _{0 \leq y_{1} \leq K}\left\{P_{1}\left(y_{1}\right)+\min _{0 \leq \sum_{1=2}^{M} \mathrm{x}_{11} \prec K-y} \sum_{1=2}^{\mathrm{M}} \mathrm{P}_{11} \cdot\left(\mathrm{x}_{11}\right)\right\}
$$

Here: (14) $\mathrm{P}_{1}\left(\mathrm{Y}_{1}\right)=\min _{\mathrm{j}=1, \mathrm{n}}\left\{R_{1 j} \cdot\left(Y_{1}\right)\right\}$

Applications of minimizing includes the $\min _{i}\left\{a_{i}+b\right\}=\min _{i}\left(a_{i}\right)+b$ and because of

$$
\min _{j}\left\{\min _{0 \leq x_{1 j} \leq k}\left\{R_{1 j}\left(x_{i j}\right)+\min _{0 \leq \sum_{1=2}^{m} x_{1 j} \leq k-x_{i j}} \sum_{i=2}^{m} R_{i 1}\left(x_{i 1}\right)\right\}=\min _{0 \leq x_{1 j} \leq k}\left\{p_{1}\left(y_{1}\right)+\min _{0 \leq \sum_{i=2}^{m} x_{1 j} \leq k-x_{i j}} \sum_{i=2}^{m} R_{i 1}\left(x_{i 1}\right)\right\}\right.
$$

that:

$\mathrm{Y}_{1}$ accepts the $\mathrm{x}_{1}$ place as the new variable in minimizing issue (14); that is, in (14), if minimum is in each index $\mathrm{Y}_{1}$ is a variable which takes the $\mathrm{x}_{\mathrm{ij}}$.

Since the identity of issue (13)-(14) is an issue which determines the stocks which are 
used in portfolio from among the stock groups in $\mathrm{n}$ numbers; that is, the stocks which are specialized to primary portfolio should be from stocks which include the less risk against the specialized capital $Y_{1}, 0 \leq y_{1} \leq k$, for these stocks.

It is necessary to state that, the selected group of stocks depended on the value of capital can be variable.

Therefore, by simplifying the structure of issue (4)-(7) as it was mentioned above, instead of solutions with $\mathrm{n}$ numbers, it is possible to finish the above issue with one solution.

We will call these changing processes as the "standard regression process".

In the next step by using this "standard regression process" about other options in each step, we will replace a solution option will be replaced $n$ number solution option. For example, if in the frequency $\mathrm{T}(\mathrm{A})$ just one of the details of matrix's first line equals one and from the second line $a_{22}=1$ and the rest ones equal with zero and the standard regression process about issues which supply condition $a_{i 1}=1, \quad a_{i j}=0, \quad i=\overline{1, n}, \quad j=\overline{2, n}$ for rest of lines of matrix.

Issue for the n numbers

$$
\min _{0 \leq y_{1} \leq K}\left\{P_{1}\left(y_{1}\right)+\underset{0 \leq x_{22}+\sum_{1=2}^{M} \mathrm{x}_{13} \prec K-y_{1}}{\min } R_{22}\left(x_{22}\right)+\sum_{\mathrm{j}=2}^{\mathrm{M}} \mathrm{P}_{\mathrm{i} 1} \cdot\left(\mathrm{x}_{\mathrm{i} 1}\right)\right\}
$$

If the reduced standard methods are applied about other groups of matrix $a_{23}=1, a_{2 j}=0, j=3$, and the other details like first step, so we have:

$$
\min _{0 \leq y_{1} \leq K}\left\{P_{1}\left(y_{1}\right)+\underset{0 \leq x_{23}+\sum_{\mathrm{l}=2}^{\mathrm{M}} \mathrm{x}_{13} \cdot \prec K-y_{1}}{\min } R_{23}\left(x_{3}\right)+\sum_{\mathrm{j}=3}^{\mathrm{M}} \mathrm{P}_{\mathrm{i} 1} \cdot\left(\mathrm{x}_{\mathrm{i} 1}\right)\right\}
$$

By applying the standard regression method about the optimal distribution of capital issues suitable with all groups of matrixes, issues from (15)-(16) types in $n^{m-1}$ number will be accessed. These issues can be regressed about issues in $n^{m-2}$ numbers like below

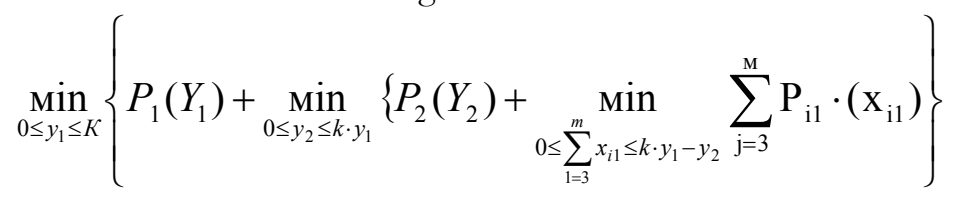

Regression And here

$$
P_{2}\left(Y_{2}\right)=\max _{j=1, n}\left\{R_{2 j} \cdot\left(Y_{2}\right)\right\}
$$

Applying the standard regression about issues like (3.31) are resulted as the final result which is shown below 


$$
\begin{aligned}
& \min _{0 \leq y_{1} \leq k}\left\{P_{1}\left(Y_{1}\right)+\min _{0 \leq y_{2} \leq k-y_{1}} P_{2}\left(Y_{2}\right)+\ldots .+\min _{0 \leq y_{m} \leq k-\sum_{n-1}^{m-1} y_{1}} P_{m}\left(Y_{m}\right)\right\} \\
& P_{i}\left(Y_{i}\right)=\min _{j=1, n}\left\{R_{i j} \cdot\left(Y_{i}\right)\right\}
\end{aligned}
$$

This is the other type of below issue:

$$
\begin{gathered}
\sum_{i=1}^{m} P_{i}\left(Y_{i}\right) \rightarrow \min \\
\sum_{i=1}^{m} Y_{i}=K \\
Y_{i} \geq 0, \quad i=\overline{1, m}
\end{gathered}
$$

It can be said that here we showed that the issue (4-7) equals with issue (20-22). This position will make it possible solve the issue (4-7) in 2 steps:

First step: forming the functions $P_{i}\left(Y_{i}\right), i=\overline{1, m}$

by unequal relationship (22). It should be considered that with lack of possibility for finding functions $P_{i}\left(Y_{i}\right)$ by analyzing, it is possible to discrete $[0, K]$ the part by special steps and calculate for each functional group.

The second step: $P_{i}\left(Y_{i}\right)$ solving the issue (20-21) with special methods, like by dynamic planning which from simplicity points of view of algorithm and the weight, the functions' $P_{i}\left(Y_{i}\right)$ conditions are calculated from effective methods.

It is important to mention that in issue (4-7), two parameters- optimal matrix $A^{*}$ which is a matrix which determines from which group the stocks are specialized for which investment and suitable for matrix, determining the value of capital $\mathrm{X}_{\mathrm{i}}$ for distributing the optimal capital among the stocks is sought, while in issue (20-22), the single method for finding the style of optimal distribution of capital among the stock is considered, but in real the equality of (22) will help to determine the optimal distribution of capital with elements suitable to matrix A*.

Investors in investment and forming the portfolio mainly tow parameters which are profitability and investment risk should be considered, and in base of these two parameters it would be tried to solve the optimization issues. In base of proved case, solving this two-criterion issue as (effective-weak) can apply to solve the mono-criterion optimization about second parameter with limiting one of the parameters. In cases in base of necessity of financial organizations, companies and mega-corporation 
and ... apply to create the investment portfolios. The main goal of forming the portfolios is that the determining parameters have the optimal quality. The multiportfolio models in financial marketing with different characteristics can be formed in different cases.

The issue of minimizing the risk in ineffective markets in conditions which risk portfolio depends on the value of determined capital is explored.

In cases where the risk depends on the value of the capital in linear and square, in base of reflective equations, the light access was presented for solving the issue.

If the total risk's determining function is a function which depends on two parametersmatrixes and portfolio's determined capital value, the risk reduction should be in base of two parameters.

\section{Conclusion:}

1. Total risk in multi-portfolio model can be started by a linear function which depends on the risk of all portfolios.

2. Total risk of Minimization problem is regarded as a bi-parametric non-linear optimization problem. One of these parameters is goals matrix and the other is invested amounts which are specified for providing portfolios.

3. With using the method of successive aggregation of objective, this problem aggregates like one parametric non-linear optimization problem.

4. The aggregated problem can be solved by using dynamic programming.

5. In this paper M-numbers of investment stocks which include the minimum of general risk among $\mathrm{N}$-numbers of stocks are analyzed.

In this case, it is assumed that the risk of each stocks of $i$-th which is belonged to the set of $j$-th is related to these stocks with a dependent function to the degree of specified investment. The total risk of all stocks is a function of the risk of all stocks separately. This problem includes a bi-parametric non-linear optimization problem and it is available to generalize as a factor of a one parametric optimum for special type of objective.

\section{References}

Nazari, R.I., and, Mirzayov, F. (2012). "Creating the Suitable Portfolios in the Effective Financial Markets ". AMEA Journal, Economy volume, No. 3, 130-133.

Nazari, P.I., (2012). "Solving Risk Conditions Problems Optimization Problem in Portfolio Models". Australian Journal of Basic and Applied Sciences 6(9) P. 669-673.

Nazari, R. (2010). Minimizing issue in multi-sharing models (investing collections), the main problem in natural and humanistic sciences, No. 8. Pp. 136-141.

L. Glits, (1998). Financial and investment engineering, tools and financial risk management methods. P. 576. Chiterkin, E.N. (2010). Financial mathematics and investing. P. 430.

Sharp, O. and Alexander J. B. (2007). Investing. P. 1028.

Nazari, P.I., (2012). About Reducing the Risk in Investing Projects in Pp. 330, 341-344. 